\title{
Modeling and Parametric Identification of a Variable-Displacement Pressure- Compensated Pump
}

\author{
Filipe Spuri and Luiz Goes* \\ Mechanical Engineering Division, Instituto Tecnológico de Aeronáutica, ITA, São José dos Campos, São Paulo/Brazil \\ E-mail: filipespuri@gmail.com,goes@ita.br
}

\begin{abstract}
This work deals with bond-graph modeling and identification of variable-displacement pressure-compensated pump using a gray-box modeling approach. The model structure is defined using the bond graph technique, a graphical representation based on flow of energy in the system, which is implemented in the 20 -sim software. The bond graph model is converted to state-space representation and the unknown parameters of equations of state are estimated applying parametric identification technique, the Prediction Error Method (PEM) on the SITB (System Identification Toolbox) MATLAB $^{\circledR}$ software. The obtained model is validated collecting an experimental data set on test rig and comparing to simulation results.
\end{abstract}

Keywords: bond graph, system identification, variable displacement pump

\section{Introduction}

A variable displacement pressure compensated pump provides nearly constant pressure through the entire flow range (from zero to full flow). In aircraft systems, this type of hydraulic pump is typically used for hydraulic power generation, since for different flight phases the hydraulic demand varies and the hydraulic consumers such as control surface actuators require a minimum pressure for deflection of surfaces. The system is capable to adapt to a given aerodynamic load, and to maintain the desired performance.

The design definitions of a hydraulic pump plays a very important role to meet the requirements of a hydraulic supply system in order to satisfy the needs of the hydraulic consumers, such as to guarantee a minimum pressure and minimum time interval to reach the steady state pressure for variation of the load in the system. The use of a mathematical model for the design of a hydraulic pump or the analysis in the integrated hydraulic system is very useful to performance analysis, definition and sensitivity analysis of design parameters.

This work aims to develop a variable-displacement pressurecompensated pump model using the graphical modeling approach, based on bond-graph, which in conjunction with the Prediction Error Method (PEM), can be used to estimate the unknown hydraulic physical parameters. Delgado and Garcia [1] have implemented a software package DESIS that consists of a parametric identification module using the bond graph technique to represent the model structure.

In [2], Casoli and Anthony have developed a model of load sensing variable displacement pump using the bond graph methodology realized through the AMESim ${ }^{\circledR}$ simulation software. The white box modeling approach was used to model the flow compensator and pressure compensator, while the pump (control piston and swash plate) was modeled through the black box modeling by means of the correlation between control piston pressure and the system pressure.

Li and Thurner [3] have proposed the combination of black and grey box model identification to multi-axial testing systems with servo-hydraulic test cylinders. In this method, a white box model of the whole system is built and the unknown parameters are roughly estimated according to previous experience. To improve the white box model, the black box model identification is applied in order to adjust some model parameter estimates. Lastly, the grey box model identification is realized using the improved model as a new initial model. This approach is useful when the initial value of unknown system parameters cannot be accurately estimated.

In addition, two modeling techniques for variable piston pump are proposed in [4]: a black box model of the swash plate dynamic identified by performing a frequency response test and analysis, using a linear transfer function; and a non-linear grey box model, where all the unknown model parameters have been identified through non-linear optimization in MATLAB. Both approaches results in models with a good accuracy. However the grey box model has presented the best non-linear model of the swash plate angle control circuit.

In [5], the results of a systematic research for basic hydrostatic system containing a servo pump with different types of controls are presented. Theoretical models are developed by AMESim $^{\circledR}$ and the experimental tests are performed using LabVIEW software. 
In this work, the grey box system identification is applied to the state space model of a variable displacement pump integrated with the pressure compensator valve, which is obtained by the bond-graph method.

The alternative white box system identification technique is based on the physics of the process studied, and the perfect knowledge of the physical parameters, but the detailed knowledge of the system required to obtain accurate models are not usually known. In order to overcome these problems, the parameter estimation of the systems is used to obtain an accurate mathematical model of the processes under study.

The black box modeling is a system identification approach based on input/output model ("curve fitting"), with no prior knowledge of the physics of the process. However the model and its parameters have little physical significance. The gray box modeling approach combines prior physical knowledge (white box) with input/output data information (black box). In this case, the model may be not completely described by the physical equations, but equations and parameters are physically interpretable. One of advantages of grey box modeling is that missing data and noise are easily dealt; in addition it is possible to estimate environmental variables that are not directly measured.

The motivation to use the bond-graph approach as physical representation is that the graphical representation is very close to the physical system, making clear the relationship between the components of the system. Additionally, it allows working with different energy domains (mechanical / hydraulic) in a direct way, as in the development of the hydraulic pump model. The mathematical formalism intrinsic to it allows evaluating the quality of the model, such as the existence of an algebraic loop and differential causality that causes undesirable behaviors to the model, and also allows obtaining of state equations by means of algorithm, model structure used to apply the parametric identification method.

\section{Variable-displacement pressure- compensated pump}

The variable displacement pressure compensated pump is essentially comprised of a three-way pilot valve (pressure compensator valve) and a piston with spring return (control piston), that controls the tilt angle of swash plate [6] as presented in fig. 1 and fig. 2.

Initially, considering that there is no load (resistance to flow) in the system, the pump pressure is zero and the displacement is maximized due to the maximum swash plate angle. As the load increases the pressure consequently increases. The pump flow is at maximum until the pressure reaches the pressure adjusted by the compensator valve spring. A pressure above the setting causes the spool valve displacement allowing the flow to the control piston and decreasing the swash plate angle. Consequently, the pump flow decreases until the system reaches the pressure setting again. In case of decreasing load, the pressure decreases causing displacement of the control piston, so that it allows the flow from this to the return line, increasing the swash plate angle, thus the flow delivered by pump increases until the pressure setting is reached $[8,9]$.

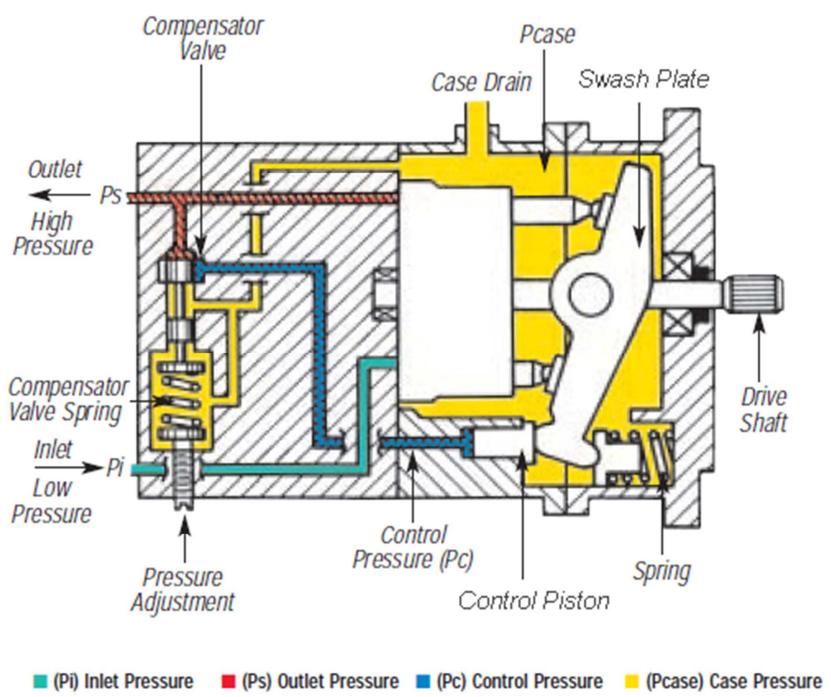

Figure 1:Cross-sectional view of variable-displacement pressure-compensated pump [7].

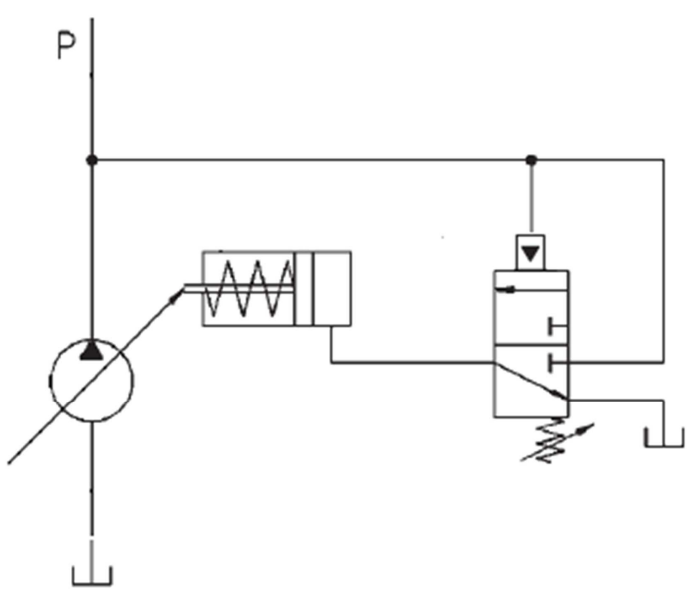

Figure 2: ISO schematic diagram of variable displacement pump with pressure compensator valve.

\subsection{Bond-Graph model}

Using the 20-sim software [10], a graphical representation of the energy bonds is represented $[11,12,13]$, as shown in fig.3. 


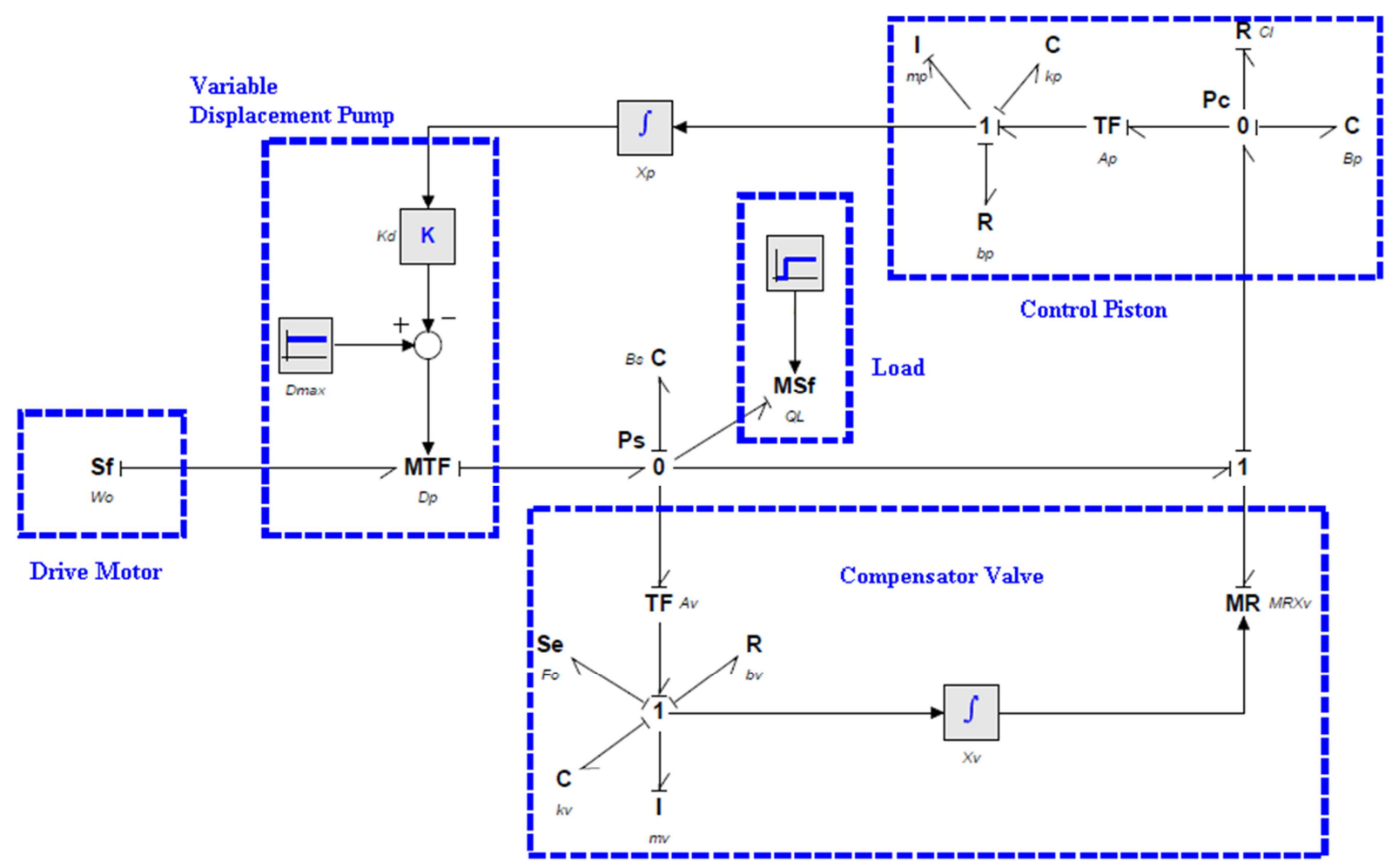

Figure 3: Bond Graph representation of variable-displacement pressure-compensated pump.

The compensator valve is modeled by the transformer element $T F: A_{v}$ that represents the area effect of the valve, which transforms the pump outlet pressure into a force acting upon the mass of the valve. To generate a displacement of the valve it is needed to overcome the force of the spring preload adjusted on compensator valve, represented by the effort source $\mathrm{Se}: F_{0}$, where the $F_{0}$ is calculated according to eq. (1) considering the pump setting pressure, $P_{s a}$. The orifice of the compensator valve is modeled as a resistor modulated by the valve position, $M R: x_{v}$, defined as orifice equation eq. (2). Using Taylor series expansion and considering pressure gain $K_{c}<<0$, the linearized form of equation is presented in eq.(3).

$$
\begin{gathered}
F_{0}=P_{s a} \cdot A_{v} \\
Q_{v}=C_{d} \cdot A_{w} \cdot X_{v} \cdot \sqrt{\frac{2}{\rho} \Delta P \operatorname{sign}(\Delta P)} \\
\Delta Q_{v}=K_{q} \cdot \Delta X_{v}
\end{gathered}
$$

The control piston chamber is represented by storage node C-type, $C: B_{\mathrm{p}}$, where the fluid compressibility $B_{p}$ is defined in eq. (4). The capacitance of the fluid generates a pressure on the area of the piston defined by the transformer element $T F: A_{p}$.

$$
B_{p}=\frac{V_{p}}{\beta}
$$

The flow generated by the pump rotation is represented by $M T F: D_{p}$, a transformer element modulated by the volumetric displacement of the pump, which is calculated according to eq. (5), based on the displacement of the control piston $x_{p}$ and the displacement gradient of the pump $K_{d}$.

$$
D_{p}=D_{\max }-K_{d} \cdot X_{p}
$$

Lastly, the flow demanded by hydraulic load is modeled using the representation of a modulated flow source, $M s f: Q_{L}$, which represents the flow demand variation. In addition, the capacitive effect at the pump outlet due to fluid compressibility is represented in eq. (6).

$$
B_{s}=\frac{V_{t}}{\beta}
$$




\subsection{State space model}

From the bond graph model, the state equations system is obtained by a systematic approach. Using the 20 -sim software, the dynamic equations are defined and put in the state space form. Six state variables are required for the system representation, since the system has six energy storage elements. The state variables are defined in eq. (7) as state vector.

$$
x(t)=\left[\begin{array}{l}
x_{1}(t) \\
x_{2}(t) \\
x_{3}(t) \\
x_{4}(t) \\
x_{5}(t) \\
x_{6}(t)
\end{array}\right]=\left[\begin{array}{c}
P_{c}(t) \\
P_{s}(t) \\
x_{p}(t) \\
x_{v}(t) \\
\dot{x}_{p}(t) \\
\dot{x}_{v}(t)
\end{array}\right]
$$

The input vector $\mathrm{u}(\mathrm{t})$, according to eq. (8), is composed of the pressure compensator spring preload, $F_{0}$; the rotational speed of the drive motor, $W_{0}$; and the flow $Q_{L}$ demanded by the hydraulic load.

$$
u(t)=\left[\begin{array}{l}
u_{1}(t) \\
u_{2}(t) \\
u_{3}(t)
\end{array}\right]=\left[\begin{array}{l}
F_{0}(t) \\
W_{0}(t) \\
Q_{L}(t)
\end{array}\right]
$$

Through the flow balance at the common effort junctions ( 0 junction) and the effort balance at the common flow junctions (junction 1) the state equations eq. (9), eq. (10), eq. (11), eq. (12), eq. (13) and eq. (14) are obtained.

$$
\begin{gathered}
\dot{x}_{1}=\frac{1}{B_{p}} \cdot\left[-\frac{1}{C_{l}} \cdot x_{1}+K_{q} x_{4}-A_{p} \cdot x_{5}\right] \\
\dot{x}_{2}=\frac{1}{B_{s}} \cdot\left[u_{2} \cdot\left(D_{\max }-K_{d} \cdot x_{3}\right)-K_{q} x_{4}-A_{v} \cdot x_{6}-u_{3}\right] \\
\dot{x}_{3}=x_{5} \\
\dot{x}_{4}=x_{6} \\
\dot{x}_{5}=\frac{1}{m_{p}} \cdot\left[A_{p} \cdot x_{1}-K_{p} \cdot x_{3}-b_{p} \cdot x_{5}\right] \\
\dot{x}_{6}=\frac{1}{m_{v}} \cdot\left[A_{v} \cdot x_{2}-K_{v} \cdot x_{4}-b_{v} \cdot x_{6}-u_{1}\right]
\end{gathered}
$$

Linearizing the equations at the operating point $W_{0 e}$ and $x_{p 0}$, the equations in the state space form is defined according to eq. (15), eq. (16), eq. (17), eq. (18) and eq. (19).

$$
\left\{\begin{array}{l}
\dot{x}(t)=A \cdot x(t)+B \cdot u(t) \\
y(t)=C \cdot x(t)+D \cdot u(t)
\end{array}\right.
$$

$$
A=\left[\begin{array}{cccccc}
-\frac{1}{B_{p} \cdot C_{l}} & 0 & 0 & \frac{K_{q}}{B_{p}} & -\frac{A_{p}}{B_{p}} & 0 \\
0 & 0 & -\frac{K_{d} \cdot W_{0 e}}{B_{s}} & -\frac{K_{q}}{B_{s}} & 0 & -\frac{A_{v}}{B_{s}} \\
0 & 0 & 0 & 0 & 1 & 0 \\
0 & 0 & 0 & 0 & 0 & 1 \\
\frac{A_{p}}{m_{p}} & 0 & -\frac{K_{p}}{m_{p}} & 0 & -\frac{b_{p}}{m_{p}} & 0 \\
0 & \frac{A_{v}}{m_{v}} & 0 & -\frac{K_{v}}{m_{v}} & 0 & -\frac{b_{v}}{m_{v}}
\end{array}\right]
$$

$$
B=\left[\begin{array}{ccc}
0 & 0 & 0 \\
0 & \frac{\left(D_{\max }-X_{p 0} \cdot K_{d}\right)}{B_{s}} & -\frac{1}{B_{s}} \\
0 & 0 & 0 \\
0 & 0 & 0 \\
0 & 0 & 0 \\
-\frac{1}{m_{v}} & 0 & 0
\end{array}\right]
$$

$$
C=\left[\begin{array}{llllll}
0 & 1 & 0 & 0 & 0 & 0
\end{array}\right]
$$

$$
D=\left[\begin{array}{lll}
0 & 0 & 0
\end{array}\right]
$$

The model inputs $F_{0}$ and $W_{0}$ are defined as constant, therefore the input of model is given by the pump outlet flow $Q_{L}$ and the outlet pressure $P_{s}$ is considered as model output.

This choice of model input/output was defined in order to capture the characteristic dynamic behavior of pump for variable flow demand, specifically for aircraft hydraulic system, where the flow demand varies according to flight phase and a minimum effective pressure must be guaranteed for the correct operation of hydraulic actuators.

\section{Parametric identification}

After the state equations system is defined, using an experimental data set obtained on the test rig, the parametric identification technique is applied to estimate the values of the unknown parameters.

\subsection{Experimental setup}

The system data acquisition experiment consists of obtaining outlet pressure data for a variation of the flow demand while keeping constant the pump rotational speed. With the hydraulic pump operating at its setting pressure $\left(2.034 \times 10^{7} \mathrm{~Pa} / 2950 \mathrm{psi}\right)$, and providing the maximum flow 
rate $\left(1.61 \times 10^{-3} \mathrm{~m}^{3} / \mathrm{s} / 25.5 \mathrm{GPM}\right)$ for the operating speed ( $390 \mathrm{rad} / \mathrm{s} / 3724 \mathrm{rpm})$, the hydraulic flow demand is a step input. The fig. 4 shows the schematic diagram of the experimental setup used to obtain input and output data from the system. This is comprised of a pressure transducer to measure the outlet pressure of the pump $P_{s}$ and a flow sensor to measure the hydraulic flow demand $Q_{L}$ of the simulated load through the variable orifice valve. The rotational speed sensor of the hydraulic pump is only used to monitor the speed of rotation at the set operating point $W_{0 e}$.

The data plot of the flow demanded by the load and the pump outlet pressure, are presented in the fig. 5 and fig. 6 , respectively.

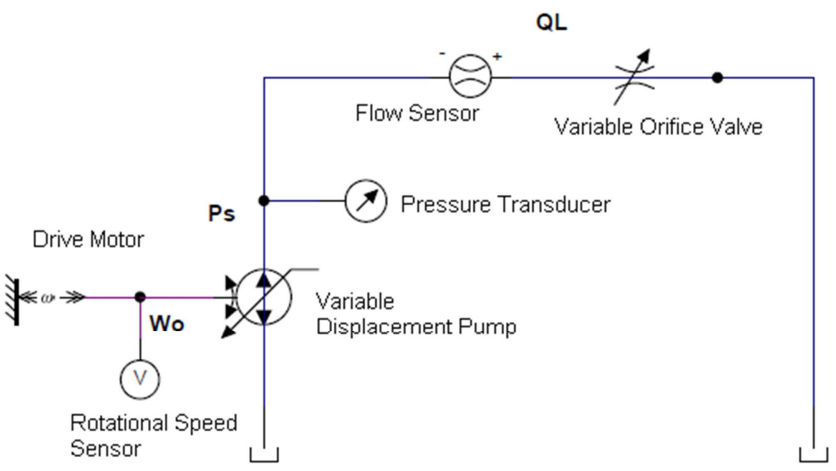

Figure 4: Schematic diagram of the rig test.

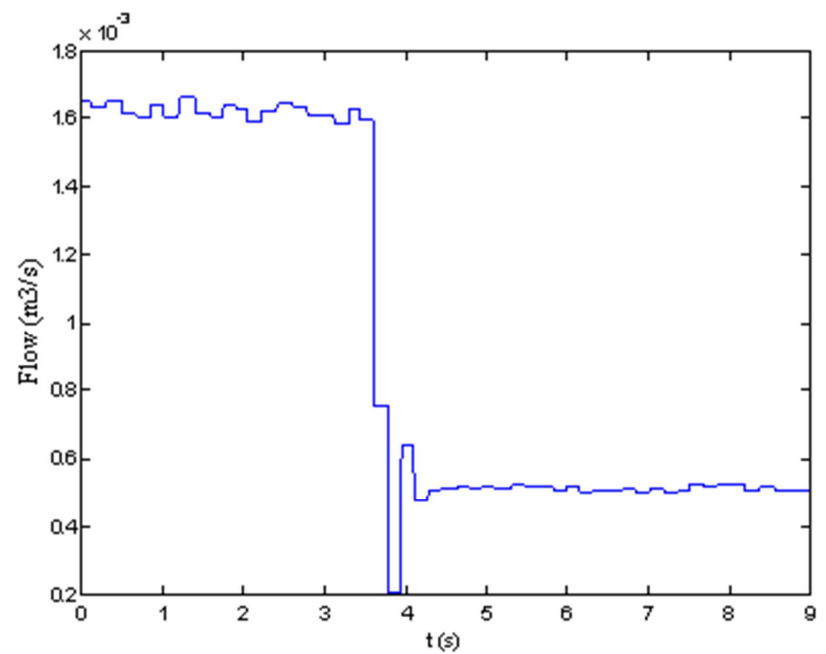

Figure 5: Hydraulic flow demanded by the load (step input).

As shown in the fig. 6 , there is a ripple in the pump outlet pressure signal due to the movement of the pistons inside the pump cylinder; however the model under study does not include the piston to modeling of the ripple effect. Therefore it is necessary the pre-processing of data in order to use it in parametric identification method.

To smooth out the pressure signal ripple, a general moving average filter, Savitzky-Golay filter [14], was used. It attempts to fit a polynomial of a specified order over a specified number of samples. Using a uniformly weighted moving average filter it is possible to remove any component that is periodic with respect to the duration of the filter.

Considering the ripple frequency $f_{r}$ and the signal sampling frequency $f_{s}$, the frame length $N_{f}$ of the filter, in number of samples is defined according to eq. (20); and the ripple frequency is estimated using the eq. (21) as presented in [15].

$$
N_{f}=\frac{f_{s}}{f_{r}}
$$

$$
f_{r}=\frac{N_{o}}{2 \pi} W_{0}
$$

Figure 7 shows the outlet pressure curve of the hydraulic pump after the filtering.

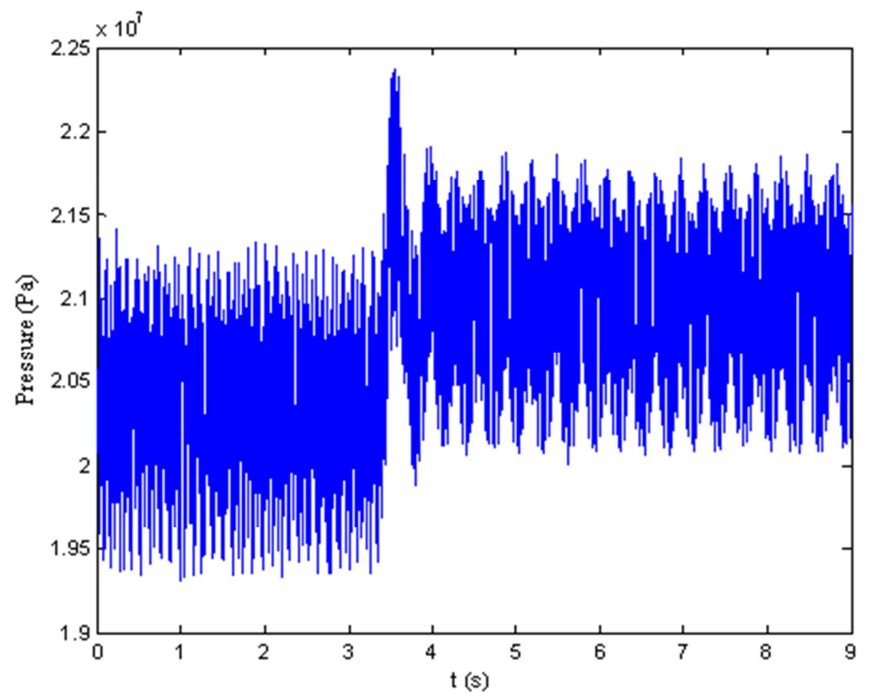

Figure 6: Pump outlet pressure.

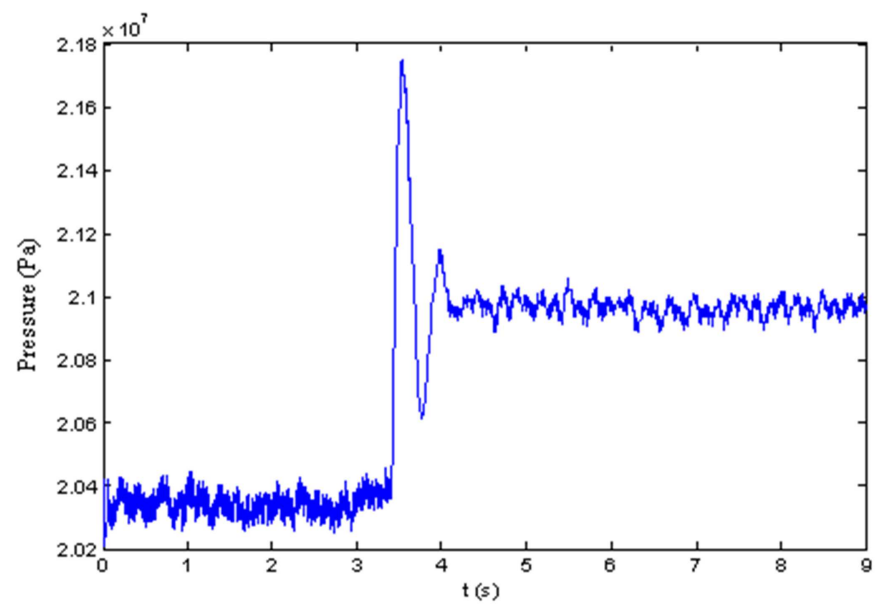

Figure 7: Filtered pump outlet pressure. 


\subsection{Parameter estimation}

It is considered a set of candidate models to represent a system and a set of data obtained experimentally on the system under study, defined in eq. (22) and eq. (23) respectively.

$$
\begin{gathered}
\mu^{*}=\left\{\mu(\theta) \mid \theta \in D_{\mu}\right\} \\
Z^{N}=[y(1), u(1), y(2), u(2), \ldots, y(N), u(N)]
\end{gathered}
$$

According to Ljung [16], the estimation of the vector of parameters $\theta$, consequently of the model $\mu(\hat{\theta})$ defined in $\mu^{*}$ consists in performing the mapping of $Z^{N}$ in $D_{\mu}$ as defined in eq. (24). Such mapping consists of the parameter estimation method.

$$
Z^{N} \rightarrow \hat{\theta}_{N} \in D_{\mu}
$$

The model can be seen as a way to predict the output $y(t)$ of a $Z^{N}$ data set, where $\hat{y}(t \mid \theta)$ is a prediction of the output $\mathrm{y}(\mathrm{t})$ determined by a candidate model $\mu(\theta)$. In this way, the prediction error can be defined according to eq. (25):

$$
e(t, \theta)=y(t)-\widehat{y}(t \mid \theta)
$$

A model is considered good when produces small prediction errors, however, it is necessary to define criterion for the predictor function. Defining a scalar value function $\mathrm{R}(\theta)$, called the criterion function and applying a norm is defined the eq. (26).

$$
V_{N}\left(\theta, Z^{N}\right)=\frac{1}{N} \sum_{t=1}^{N} R\left(e_{f}(t, \theta)\right)
$$

Thus, the problem of estimating the parameters of the model becomes an optimization problem that consists of the minimization of the criterion function, as defined in eq. (27).

$$
\widehat{\theta}_{N}=\arg \min V_{N}\left(\theta, Z^{N}\right)
$$

This method is known as prediction error method (PEM). In summary, this process consists of three steps: choosing the structure of the model, choosing the criterion (defining the scalar value function $\mathrm{R}(\theta)$ ) and minimization of the criterion function.
The criterion function chosen for PEM application is the covariance matrix of the prediction error, given by eq. (28). Assuming that the prediction error follows a Gaussian distribution, the optimal parameter vector $\theta$ should minimize the covariance matrix of $\mathrm{e}(\mathrm{t}, \theta)$.

$$
R_{N}(\theta)=\frac{1}{N} \sum_{t=1}^{N} e(t, \theta) \cdot e^{T}(t, \theta)
$$

Since the criterion function must be a scalar value, $R_{N}(\theta)$ can only be applied directly when $e(t, \theta)$ is a scalar sequence. For the case where the system has more than one output it is necessary to map $R_{N}(\theta)$ to a scalar, we can then define this mapping function as in eq. (29) for applying the criterion in the general case.

$$
h\left(R_{N}(\theta)\right)=\operatorname{det}\left(R_{N}(\theta)\right)
$$

The choice of this criterion function from the statistical point of view is considered optimal, since it leads to maximum likelihood for prediction errors with Gaussian distribution as presented in Ljung [16].

Using the criterion function (eq. 29), the estimation of the parameter vector is given by the minimization of it, as defined in eq. (30).

$$
\hat{\theta}_{N}=\arg \min \operatorname{det}\left(\frac{1}{N} \sum_{t=1}^{N} e(t, \theta) \cdot e^{T}(t, \theta)\right)
$$

To minimize the criterion function, the Gauss-Newton method was considered. As presented by Soderstrom and Stoica [17], this method uses a numerical search routine called the Newton-Raphson algorithm.

The Gauss-Newton method generally presents a linear convergence, however if the model is defined with more parameters than necessary, the approximate Hessian becomes very close to a singular matrix, with inversion problems occurring. In general, when the model structure is correctly selected and a good initial estimate of the parameters is available, the algorithm converges rapidly, called superlinear convergence.

The script used to estimate the parameters is presented in fig. 8. This is developed in the System Identification Toolbox [18] of MATLAB ${ }^{\circledR}$ software, making use of the pem (data, mi) function. The argument data contains the input $(F O, W O$ and $Q L)$ and the output $(P S)$ from the experimental data set. The parameter $m i$ defines the structure of the model represented by the idgrey class, composed by an instance of the function that represents the model in the state space form and the vector of free parameters, which are estimated from an initial value. The 
pem function uses the prediction error minimization method to estimate the unknown parameters.

Applying the prediction error method, the parameters are estimated. The result of the new model when compared to the experimental data shows a fit of $85.36 \%$, as shown in fig. 9 .

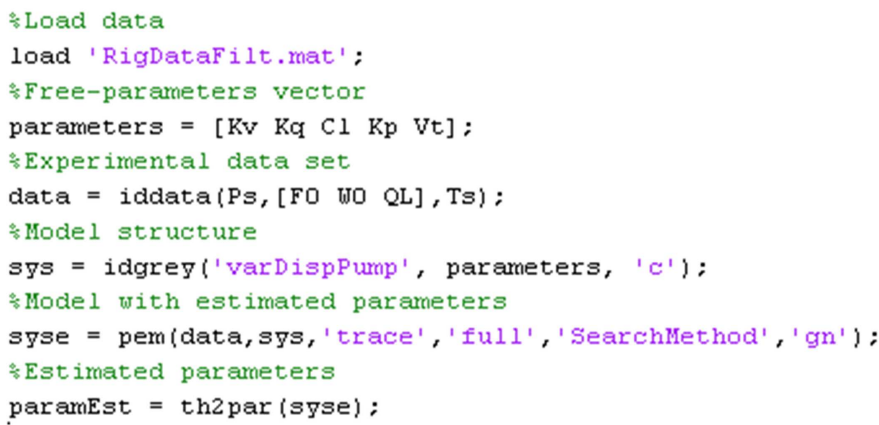

Figure 8: Script MATLAB ${ }^{\circledR}$ to estimate the model parameters.

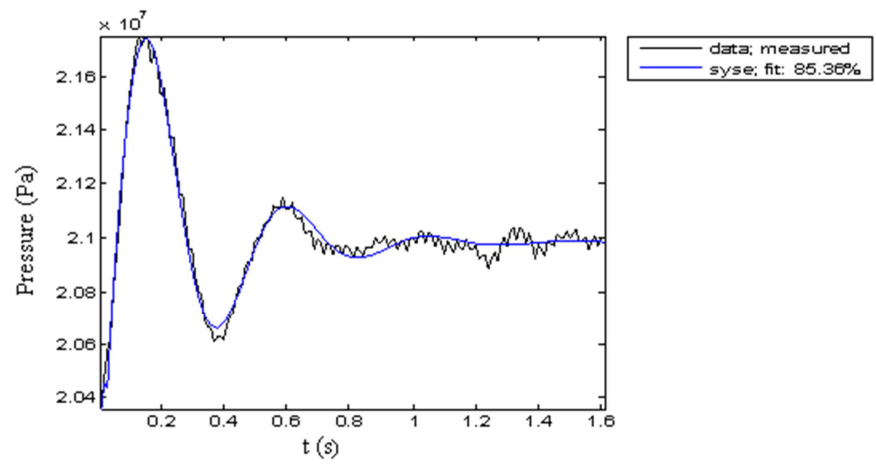

Figure 9: Comparison between the simulation and the experimental data.

\section{Validation of Simulation Model}

To validate the simulation model a different data set from that used in parametric identification is considered, in this way it is possible to verify if the model is able to represent the system for different conditions and if there is some dynamics not represented by the model. Therefore, another set of data was obtained to verify the representativeness of the model. These data were acquired considering the scenario which a flow pulse demanded by the load occurs as shown in fig. 10.

In this scenario it is expected that initially during the rising step of flow demanded should occur a reduction in the output pressure of the hydraulic pump, consequently the control piston must move in order to increase the flow delivered by the hydraulic pump. During the descent step the pressure increase and the return of the piston to the previous position should occur. Figure 11 describes the behavior of the outlet pressure of the simulated and actual pump. Even for a different scenario from which the parameters of the model were estimated, it can represent properly the dynamics of the system for which it was proposed.

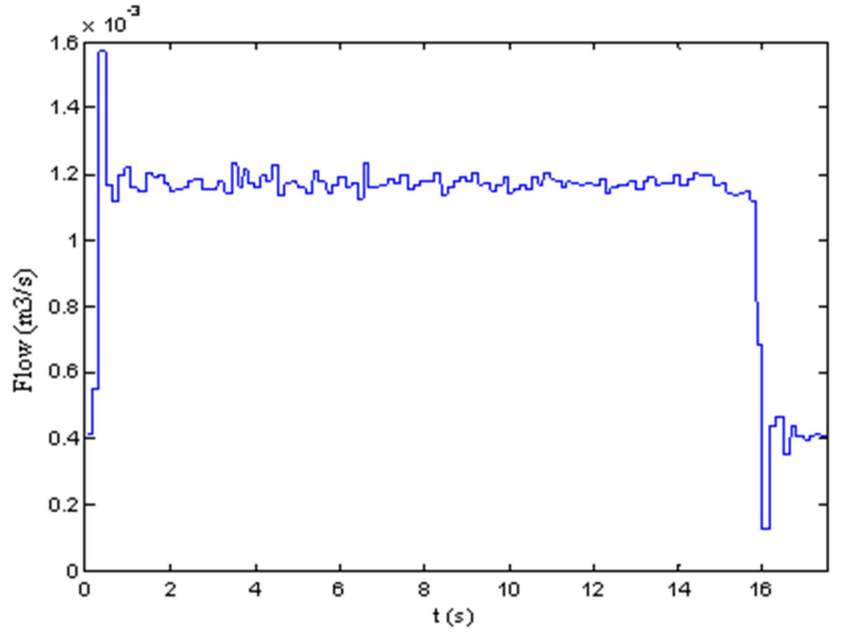

Figure 10: Flow pulse requested by the load.

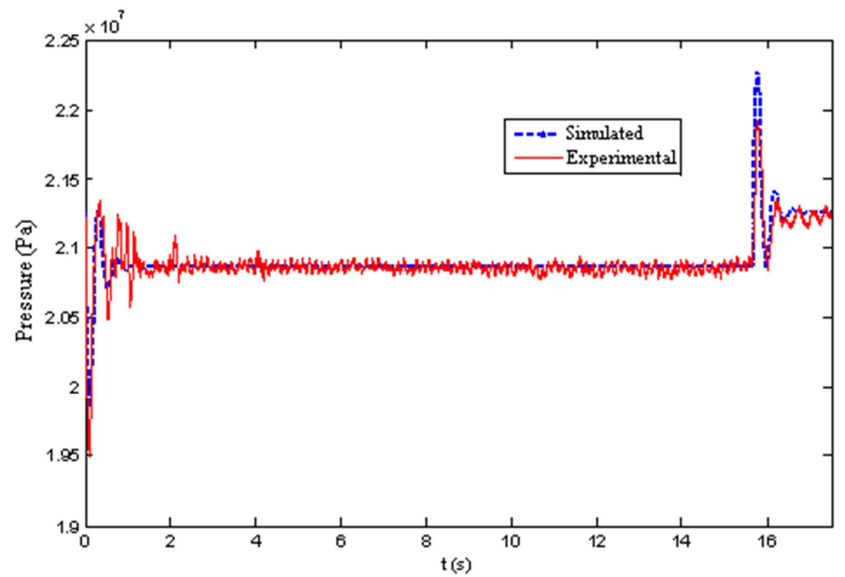

Figure 11: Comparison between the simulation and the experimental data (flow pulse).

\section{Conclusion}

The proposed goal of developing a model for a variable displacement pressure compensated hydraulic pump using the combination of physical modeling techniques and system identification was achieved. It can be observed that the combination of both, gray-box modeling, allows to obtain models more representative of the system under study. This method combines the advantages of white-box and black-box modeling, and it is possible to obtain a model without diverging from its physical meaning and also to insert in this information obtained by means of system identification. However, the application of this approach depends on the availability of data about the system that are not always available, either because of the difficulty of acquiring data with the required quality or even when it is not possible, such as during the project which the system does not yet exist.

Regarding the parametric identification, the prediction error method proved to be quite effective, however attention is needed in the choice of the search criteria and method, which must be adequate to the data and the structure of the 
analyzed model. In addition, the data used to identify the system should be chosen correctly, taking care that they represent properly the dynamics to be modeled.

\section{Nomenclature}

\begin{tabular}{|c|c|c|}
\hline Designation & Denotation & Unit \\
\hline$A_{v}$ & $\begin{array}{l}\text { Effective area of compensator } \\
\text { valve spool }\end{array}$ & $\mathrm{m}^{2}$ \\
\hline$A_{p}$ & Effective area of control piston & $\mathrm{m}^{2}$ \\
\hline$A_{w}$ & Gradient area & $\mathrm{m}^{2} / \mathrm{m}$ \\
\hline$b_{\mathrm{p}}$ & $\begin{array}{l}\text { Viscous friction coefficient of } \\
\text { control piston }\end{array}$ & $\mathrm{N} / \mathrm{m} / \mathrm{s}$ \\
\hline$b_{v}$ & $\begin{array}{l}\text { Viscous friction coefficient of } \\
\text { compensator valve }\end{array}$ & $\mathrm{N} / \mathrm{m} / \mathrm{s}$ \\
\hline$B_{\mathrm{p}}$ & $\begin{array}{l}\text { Fluid compressibility in control } \\
\text { piston chamber }\end{array}$ & $\mathrm{m}^{3} / \mathrm{Pa}$ \\
\hline$B_{\mathrm{S}}$ & $\begin{array}{l}\text { Fluid compressibility in hydraulic } \\
\text { pump outlet }\end{array}$ & $\mathrm{m}^{3} / \mathrm{Pa}$ \\
\hline$C_{d}$ & Discharge coefficient orifice & \\
\hline$C_{l}$ & Internal leakage coefficient & \\
\hline$D_{\max }$ & $\begin{array}{l}\text { Maximum volumetric } \\
\text { displacement of hydraulic pump }\end{array}$ & $\mathrm{m}^{3} / \mathrm{rad}$ \\
\hline$D_{\mathrm{p}}$ & $\begin{array}{l}\text { Volumetric displacement of } \\
\text { hydraulic pump }\end{array}$ & $\mathrm{m}^{3} / \mathrm{rad}$ \\
\hline$f_{r}$ & Ripple frequency & $\mathrm{Hz}$ \\
\hline$f_{s}$ & Sampling frequency & $\mathrm{Hz}$ \\
\hline$F_{0}$ & $\begin{array}{l}\text { Pre-load of compensator valve } \\
\text { spring }\end{array}$ & $\mathrm{N}$ \\
\hline$K_{d}$ & Displacement gradient of pump & $\mathrm{m}^{2} / \mathrm{rad}$ \\
\hline$K_{\mathrm{p}}$ & Spring constant of control piston & $\mathrm{N} / \mathrm{m}$ \\
\hline$K_{q}$ & $\begin{array}{l}\text { Flow gain of compensator valve } \\
\text { orifice }\end{array}$ & $\mathrm{m} / \mathrm{s}$ \\
\hline$K_{v}$ & $\begin{array}{l}\text { Spring constant of compensator } \\
\text { valve }\end{array}$ & $\mathrm{N} / \mathrm{m}$ \\
\hline$m_{\mathrm{p}}$ & Mass of control piston & $\mathrm{kg}$ \\
\hline$m_{v}$ & Mass of compensator valve spool & $\mathrm{kg}$ \\
\hline$N_{f}$ & Number of samples & \\
\hline$N_{o}$ & Number of pistons & \\
\hline$P_{S}$ & Hydraulic pump outlet pressure & $\mathrm{Pa}$ \\
\hline$P_{S a}$ & Pump setting pressure & $\mathrm{Pa}$ \\
\hline$P_{C}$ & Control pressure & $\mathrm{Pa}$ \\
\hline$Q_{L}$ & $\begin{array}{l}\text { Volumetric flow rate consumed } \\
\text { by load }\end{array}$ & $\mathrm{m}^{3} / \mathrm{s}$ \\
\hline$V_{p}$ & Volume of control piston chamber & $\mathrm{m}^{3}$ \\
\hline
\end{tabular}

$V_{t}$

$Q_{v}$

$x_{\mathrm{p}}$

$\dot{x}_{p}$

$x_{v}$

$\dot{x}_{v}$

$W_{0}$

$\beta$

$\rho$
Volume between pump outlet and compensator valve

Volumetric flow rate of compensator valve orifice

Position of control piston

Speed of control piston

Position of compensator valve

Speed of compensator valve

Rotational speed

Bulk modulus of fluid

Fluid density $\mathrm{m}^{3}$

$\mathrm{m}^{3} / \mathrm{s}$

$\mathrm{m}$

$\mathrm{m} / \mathrm{s}$

$\mathrm{m}$

$\mathrm{m} / \mathrm{s}$

$\mathrm{rad} / \mathrm{s}$

$\mathrm{N} / \mathrm{m}^{2}$

$\mathrm{kg} / \mathrm{m}^{3}$

\section{References}

[1] M Delgado, and J Garcia. Parametric identification on bond graph models. In: Systems, Man and Cybernetics. 'Systems Engineering in the Service of Humans', Conference Proceedings. Vol.1 pp 583 - 588, 1993.

[2] P Casoli, and A Anthony. Gray box modeling of an excavator's variable displacement hydraulic pump for fast simulation of excavation cycles. Control Engineering Practice.v.21, 483-494, 2013.

[3] $\mathrm{L} \mathrm{Li}$, and $\mathrm{T}$ Thurner. Accurate modeling and identification of servo-hydraulic cylinder systems in multi-axial test applications. Institute of Lightweight Design, Graz University, Austria, 2013.

[4] S S Tørdal, A Klausen. System Identification of a Variable Piston Pump and Design of a Hydraulic Load Circuit. Master's theses in Mechatronics, University of Agder, 2015.

[5] C G Negoita, D Vasiliu, N Vasiliu, and C Calinoiu. Modeling, simulation, and identification of the servo pumps. IOP Conference Series: Earth and Environmental Science, Vol.12(1), p.012054, 2010.

[6] H E Merrit. Hydraulic Control Systems. New York: Jhon Willey \& Son, 1967.

[7] EATON. A Descriptive Summary of Vickers Inline Pumps and their Applications, 2000.

[8] E E Lewis, and H Stern. Design of Hydraulic Control Systems. New York: McGraw-Hill,1962.

[9] J S Cundiff. Fluid Power Circuits and Control: Fundamentals and Applications, CRC Press, 2001.

[10]C Kleijn, M A Groothuis, H G Differ. 20-sim 4.3 Reference Manual. Controllab Products B.V., 2013. 
[11]P J Gawthrop, and D J Balance. Bond graphs in the design of engineering systems. Glasgow: University of Glasgow, 1998.

[12]D C Karnopp, D L Margolis, and R C Rosenberg. System Dynamics: A Unified Approach. John Wiley, 1990.

[13] W Borutzky, B Banard, and J U Thoma. Describing bond graph models of hydraulic components in Modelica. Mathematics and Computers in Simulation, v. 53,381-387, 2000.

[14]S J Orfandis. Introduction to Signal Processing. Englewood Cliffs, NJ: Prentice-Hall,1996.

[15] N D Manring. The Discharge Flow Ripple of an AxialPiston Swash-Plate Type Hydrostatic Pump. Journal of Dynamic Systems, Measurement, \& Control, v.122 (2), p.263-269,2000.

[16]L Ljung. System Identification: Theory for the Users, Prentice-Hall, 1987.

[17] T Soderstrom, and P Stoica. System Identification. Prentice-Hall, 1989.

[18]L Ljung. System Identification Toolbox ${ }^{\mathrm{TM}}$ User's Guide. $^{\prime}$ The MathWorks, Inc, 2014. 